\title{
COMPARISON AND DETERMINATION OF THE LEAF TEMPERATURE OF SUNFLOWER AND SAFFLOWER UNDER DROUGHT STRESS
}

\author{
Canavar, Ö. ${ }^{*}$
}

Adnan Menderes University, Faculty of Agriculture, Crop Science Department. Aydin - 09100 Turkey

Received: March 12, 2013 Accepted: December 05, 2013

\begin{abstract}
SUMMARY
Four sunflower (Tarsan, Sanbro, TR-3080 and DKF-2525) and four safflower (Remzibey, Dincer, Balci and TRE-ASL09/14) genotypes were tested in a greenhouse, sheltered from rain, under well-watered (60\% FC) and drought stress $(30 \% \mathrm{FC})$ irrigation field capacity to determine the effect of drought stress on the leaf temperature and compare the reaction responses against drought stress in terms of leaf temperature between sunflower and safflower. The effect was particularly apparent under conditions of drought stress indicating that all sunflower and safflower genotype responses gradually increase their leaf temperature under drought stress. The results of the study showed that leaf temperature of sunflower and safflower was lower than ambient temperature in both conditions. But the leaf temperature of sunflower and safflower were closer to ambient temperature under drought stress than under well-watered conditions, probably because of decreased transpiration cooling. It can also be exposed in this study that even though the leaf temperatures of safflower were generally higher than the leaf temperature of sunflower under drought stress, in general the safflower leaf temperatures in ambient conditions were higher than those of sunflower. It was found that statistical differences of the leaf and stem temperature measured by an infrared thermometer provide practically a rapid means of assessing plant water status and observe the performance of plant response to the effect of drought stress. Especially, the results revealed that the leaf temperatures of sunflower and safflower genotypes could be altered by not only drought stress but also the changing of ambient temperature and genetically property of them during the day. Therefore, to measuring of leaf temperatures should be done very carefully and should be measured on more leaves.
\end{abstract}

Key words: drought stress, leaf temperature, sunflower, safflower

* Corresponding author: Phone: +90 25677270 22/1811. Fax: +90 25677272 33; e-mail: ocanavar@adu.edu.tr;

Current address: Humboldt University, Agriculture and Horticulture Faculty, Crop Science Department. Berlin - 14195 Germany 


\section{INTRODUCTION}

A lot of research on determining which species are tolerant to drought, the tolerance mechanisms, conservation and transformation of the gene resources of the plants resistant to drought will play an important role in preventing the drought particularly caused by global warming, which is seen as the major problem for all organisms in the future. Many parameters such as proline, betaine, $\Delta^{13} \mathrm{C}$ isotope, some amino acids, phenols, and other, which are used and analysed to determine drought tolerance genotype in many crops, are very expensive and time consuming and need technical experts. Leaf temperature is an easily measured physiological parameter, which allows an indirect way to estimate plant transpiration and it is well correlated with water availability (Blum, 1989). Gates (1968) explained that environment is connected with a leaf through the flow of energy and the interaction of environment with a plant. There is no other way. Energy delivered to the plant is converted to heat within the plant, affecting the plant temperature, or energy is consumed through photochemical and thermo chemical events of the metabolic and physiological processes. Drought stress can result in decreasing leaf and root respiration in the short term (Byrla et al. 2001). Pallas et al. (1967) pointed out that leaf temperature was usually positively correlated with the light intensity and negatively correlated with transpiration and soil water. Leaf temperatures of plants under low soil water potential at the same radiant energy levels 4 hours prior to irrigation were $3.4,1.3$, and 0.50 above the ambient air temperature. However, leaf temperature does not bear a fixed relationship with air temperature. Net radiation, air movement, and the humidity of the air all affect leaf temperature, and it is therefore necessary to measure it in order fully to understand the plant's response to the given environment. Sunflower and safflower are very important oilseed crops because of their wide adaptability, suitability of mechanization, low labor need and high oil and protein contents. A lot of measurements have been made on sunlit leaves, under conditions of high radiation and partially or completely closed stomata. Under such conditions leaf temperature may exceed air temperature $\left(\mathrm{T}_{\mathrm{air}}\right)$ by several degrees (Gates, 1965; Karschon and Pinchas, 1969). Owing to that, the temperature can serve as an indicator of transpiration. If temperature measurements were combined with measurements of stomata conduct or aperture, useful information would be provided concerning leaf water status, as the leaf responds to environmental stresses. The objectives of this study were to determine the leaf temperature of sunflower and safflower, and to identify differences in their response in terms of leaf temperature under drought stress.

\section{MATERIAL AND METHOD}

Tarsan, Sanbro, TR-3080 and DKF-2525 sunflower hybrid cultivars and Remzibey, Dincer, Balcı safflower hybrid cultivars and TRE-ALS09/14 safflower breeding 
line, which are of Turkish origin, were tested in Mitschelin pots (25-cm deep and 20 $\mathrm{cm}$ dia.) in greenhouse conditions with only the natural sunlight during the summer months. The testing took place at the research greenhouse of Crop Science department of Agriculture and Horticulture Faculty in Humboldt University, Germany in 2012. The greenhouse was sheltered from rain or any water treatment, but the temperature and relative humidity belonged to the natural ambient. The changing temperature and relative humidity of greenhouse were measured three times a day, as recorded in one day after emergence in Figure $1(a, b)$.
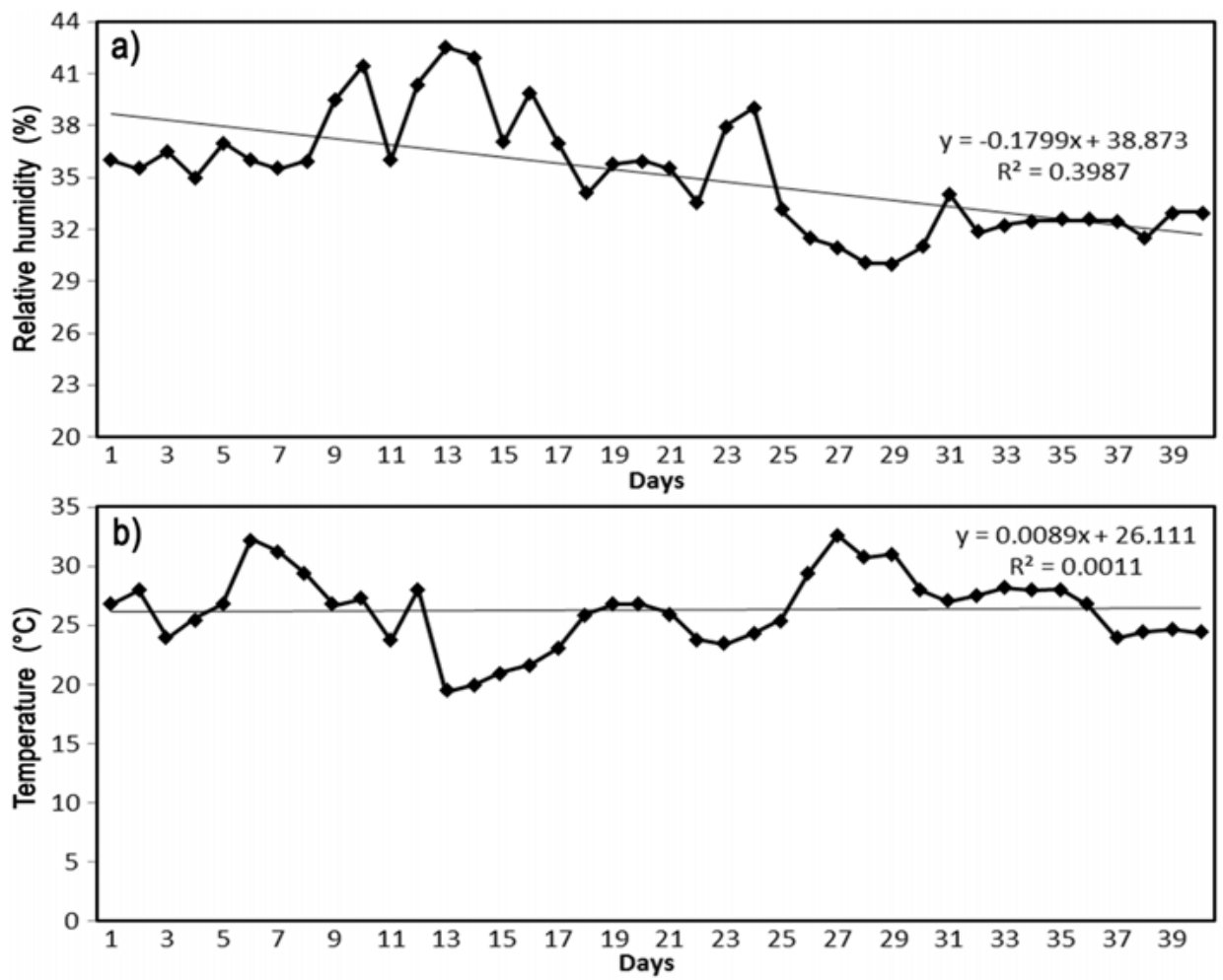

Figure 1: The mean of changing daily relative humidity $(\boldsymbol{a}, \%)$ and temperature $\left(\boldsymbol{b},{ }^{\circ} \mathrm{C}\right)$ of greenhouse were registered in 3 times daily $(8.00,12.00$ and $17.00 \mathrm{~h})$.

Clay loam soil was used to fill the pods and the cultivars were arranged completely in a randomized block design with five replications. Required amounts of chemical fertilizers were applied and seeds were sown as recommended using $1 \mathrm{~g}$ nitrogen from $3.70 \mathrm{~g}$ KAS fertilizer like the field condition. Watering started immediately after sowing and once the seedlings have emerged, thinning was carried out and the plant populations maintained ( 3 plant in pot), as recommended. Changes of soil water of each pods were measured daily by weighing each pod at the beginning and end of the removed plant. The soil water factor included two irrigation regimes, including irrigation at 30\% (Water Deficit) and 60\% (Well Watering) of field capacity. Water holding capacity was determined using gravimetric method with five repli- 
cates as amount of moisture (percentage). First, the bottoms of $100 \mathrm{~cm}^{3}$ five cylindrical tubes were covered with paper and a plastic strap for filter and then completely filled with soil (by compression). Each cylindrical tube with soil was weighed and settled in a big tray which was approximately as deep as the height of the cylindrical tube. The tray was fully filled with water up to the top of the cylindrical tube and left for $3 \mathrm{~h}$ (saturation). Then, all cylindrical tubes were left on the quartz soil for $2 \mathrm{~h}$ (for drainage and filtering). After that, all saturated cylindrical tubes were cleaned and weighed again (wet weight). Then all the tubes were ovendried at $105^{\circ} \mathrm{C} 24 \mathrm{~h}$ and the weight of the oven-dry soil samples was measured (dry weight). The field capacity of undisturbed soil was calculated according to the following formula:

$$
\text { F.C. }(\%)=\frac{\text { wet soil weight (saturated) }- \text { dry soil weight }}{\text { dry soil weight }} \times 100
$$

Soil water content of pod was continuously monitored and maintained at $30 \%$ and $60 \%$ level of field capacity by watering during experiment.

Leaf Temperature $\left({ }^{\circ} \mathrm{C}\right)$ was routinely measured above $0.5 \mathrm{~cm}$ on the leaf surface on only fully young developed leaves in all plants from 8-10 a.m. and from 1-2 p.m. twice a day during the experiment using $i$-tec 2003 Infrarot-Temperature-Messgerät DC 6V (Luneburg, Germany). Apart from that, the ambient temperature and relative humidity of greenhouse was simultaneously recorded 3 times during each measurement time (8-10 a.m. and 1-2 p.m.). LTM1 and LTN1 were measured on the $20^{\text {th }}$ day after planting and LTM2 and LTN2 were measured on the $33^{\text {rd }}$ day after planting. Stem Temperature $\left({ }^{\circ} \mathrm{C}\right)$ of sunflower hybrid cultivars was routinely measured during the same measuring leaf temperature time $\left(8-10\right.$ a.m. and 1-2 p.m.). $1^{\text {st }}$ measurement: $26^{\text {th }}$ day after planting, $2^{\text {nd }}$ measurement: $33^{\text {rd }}$ day after planting, $3^{\text {rd }}$ measurement: $40^{\text {th }}$ day after planting.

To determine the effect of drought stress on four sunflower and safflower hybrid cultivars, the samples were analyzed statistically as a randomized block design with five replications. ANOVA was applied to analyze the variance of drought stress on sunflower hybrid cultivars and the interaction of drought and cultivars. The ANOVA (analyses of variance) of this study and correlation coefficients among the traits were shown as the mean value of genotypes in each condition. The analysis was conducted using the SPSS and Tarist (Açıkgöz et al., 1994) statistical computer program.

Table 1: The result of variance analyses for sunflower leaf and stem temperature measured two times under the well-watered and drought stress conditions

\begin{tabular}{|c|c|c|c|c|c|c|c|c|c|c|}
\hline \multirow{2}{*}{$\begin{array}{l}\text { Variance } \\
\text { Source }\end{array}$} & & \multicolumn{9}{|c|}{ Calculated of Mean Square } \\
\hline & & LTM1 & LTN1 & LTM2 & STM1 & STN1 & STM2 & STN2 & STM3 & STN3 \\
\hline D.S & 1 & $6.823^{\star *}$ & $78.961 * *$ & $19.265^{\star *}$ & $7.439 * *$ & $54.920 * \star$ & $8.381^{* \star}$ & $7.405^{\star}$ & $6.906^{\star *}$ & $7.405^{\star \star}$ \\
\hline C & 3 & ns & ns & $0.731 *$ & ns & ns & ns & ns & $0.554^{\star \star}$ & $1.431^{* \star}$ \\
\hline D.S $\times C$ & 3 & ns & ns & ns & ns & $1.542^{* *}$ & ns & ns & $0.349 * *$ & 1.391 ** \\
\hline
\end{tabular}

D.S: Drought Stress, C: Cultivars, d.f.: Degree of Freedom, ns: non-significant; ${ }^{*} \mathrm{P}<0.05 ;{ }^{* *} \mathrm{P}<0.01$ LTM: Leaf Temperature Morning (8-10h), LTN: Leaf Temperature Noon (13-14h), STM: Stem Temperature Morning (8-10h), STN: Stem Temperature Noon (13-14h) 


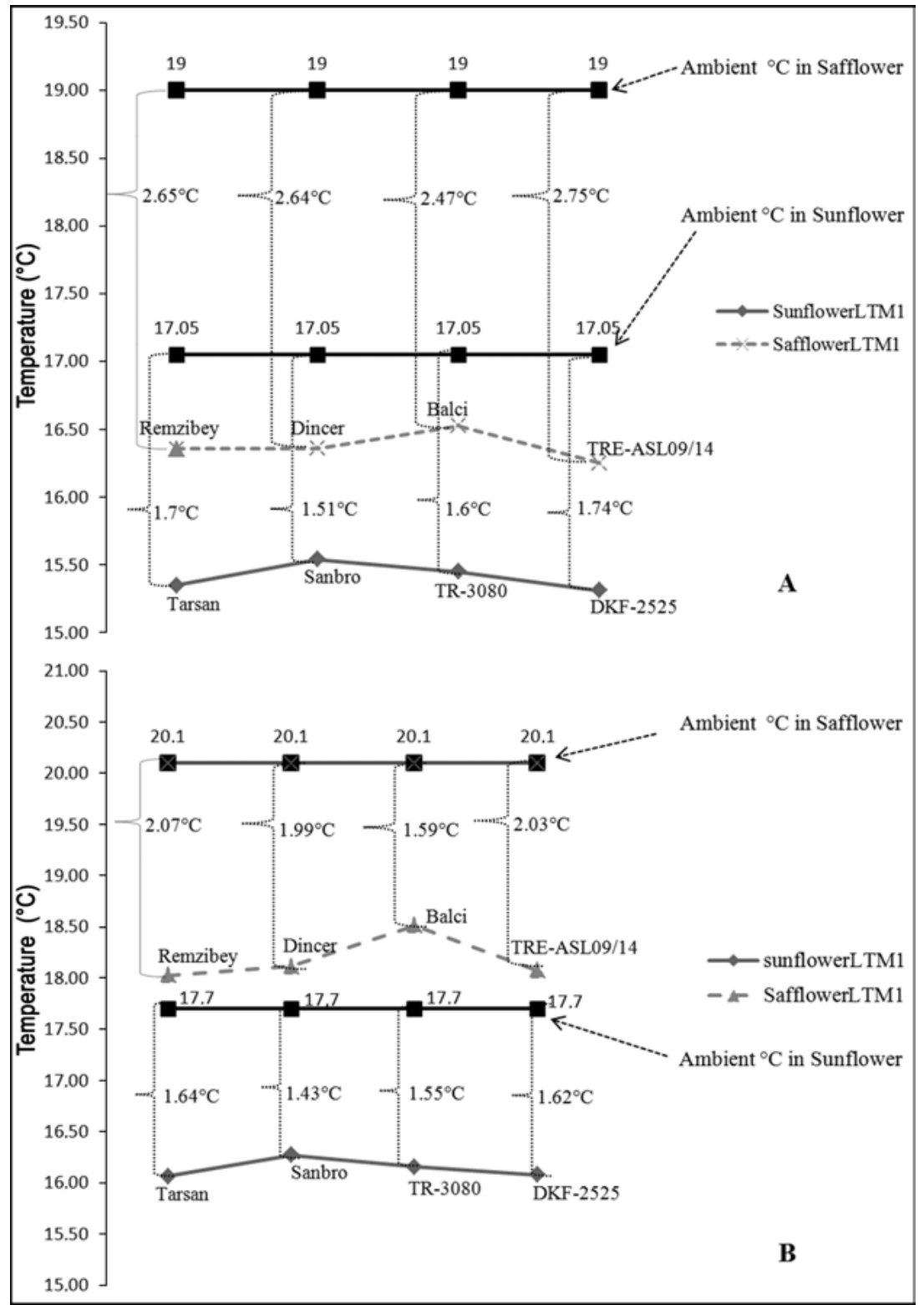

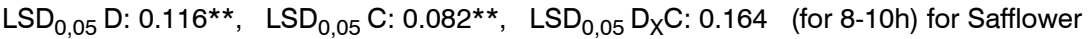
LSD $_{0,05}$ D: 0.259**, LSD 0,05 C: 0.366, LSD ${ }_{0,05} \mathrm{D}_{\mathrm{X}} \mathrm{C}: 0.517$ (for 8-10h) for Sunflower

Figure 2: Leaf temperature of young fully developed sunlit leaves of four sunflower and safflower cultivars in the $8.00-10.00 \mathrm{~h}$ (LTM1) during $17.05^{\circ} \mathrm{C}$ (for Sunflower) and $19^{\circ} \mathrm{C}$ (for safflower) ambient temperature under well-watered and drought stress. (A: well-watered, B: drought stress). LTM1 was measured at $26^{\text {th }}$ day after planting 


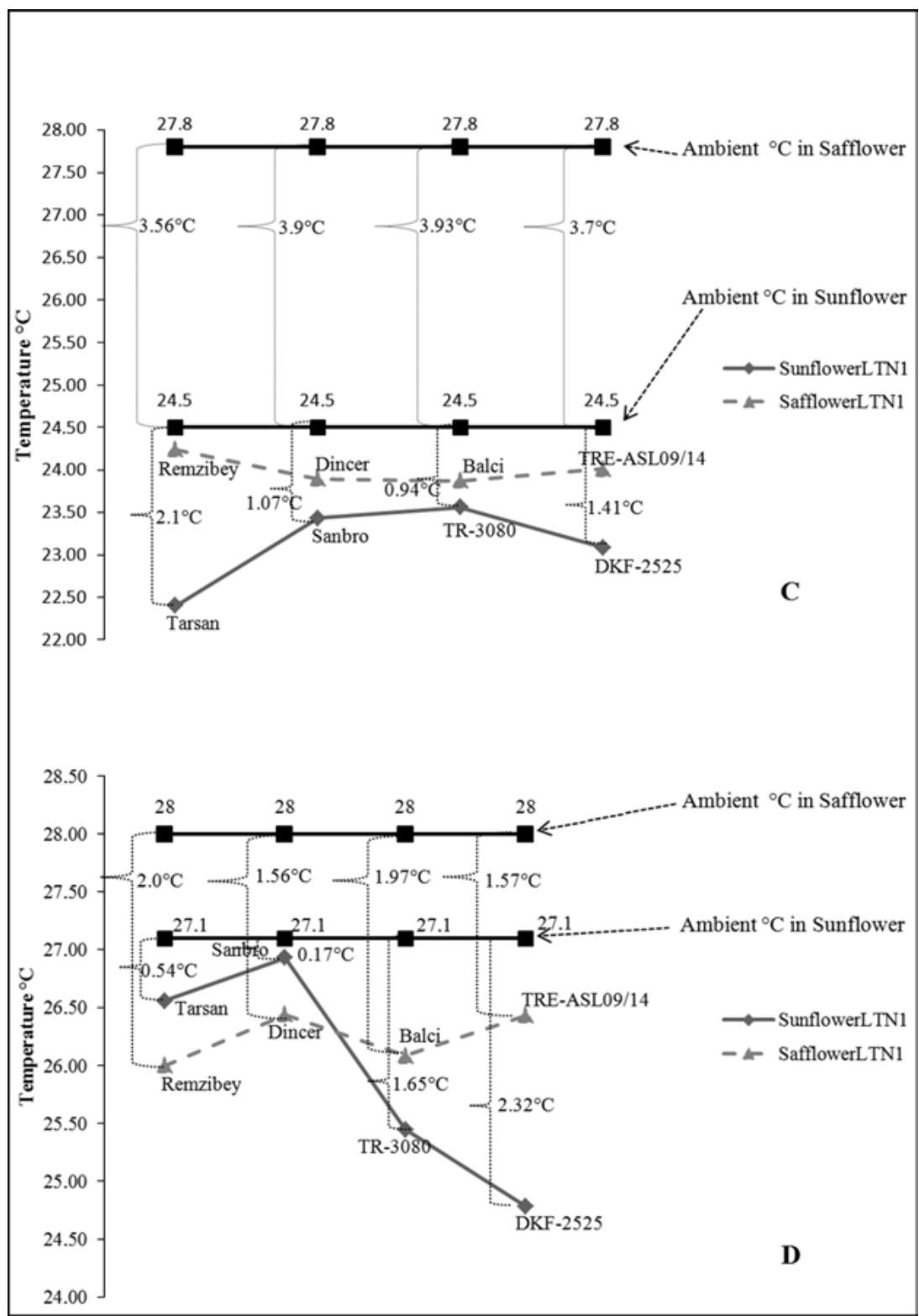

LSD $_{0,05}$ D: 1.092**, LSD ${ }_{0,05}$ C: 1.544, LSD $_{0,05} \mathrm{D}_{\mathrm{X}} \mathrm{C}: 2.184$ (for 13-14h) for Safflower LSD $_{0,05}$ D: 0.995**, LSD ${ }_{0,05}$ C: 1.407, LSD $_{0,05} \mathrm{D}_{\mathrm{X}} \mathrm{C}: 1.989$ (for 13-14h) for Sunflower

Figure 3: Leaf temperature of young fully developed sunlit leaves of four sunflower and safflower cultivars in the $13.00-14.00 \mathrm{~h}$ (LTN1) during $24.5^{\circ} \mathrm{C}$ (for Sunflower) and $27.8^{\circ} \mathrm{C}$ (for safflower) ambient temperature under well-watered and drought stress. (C: well-watered, D: drought stress). LTN1 was measured at $26^{\text {th }}$ day after planting. 


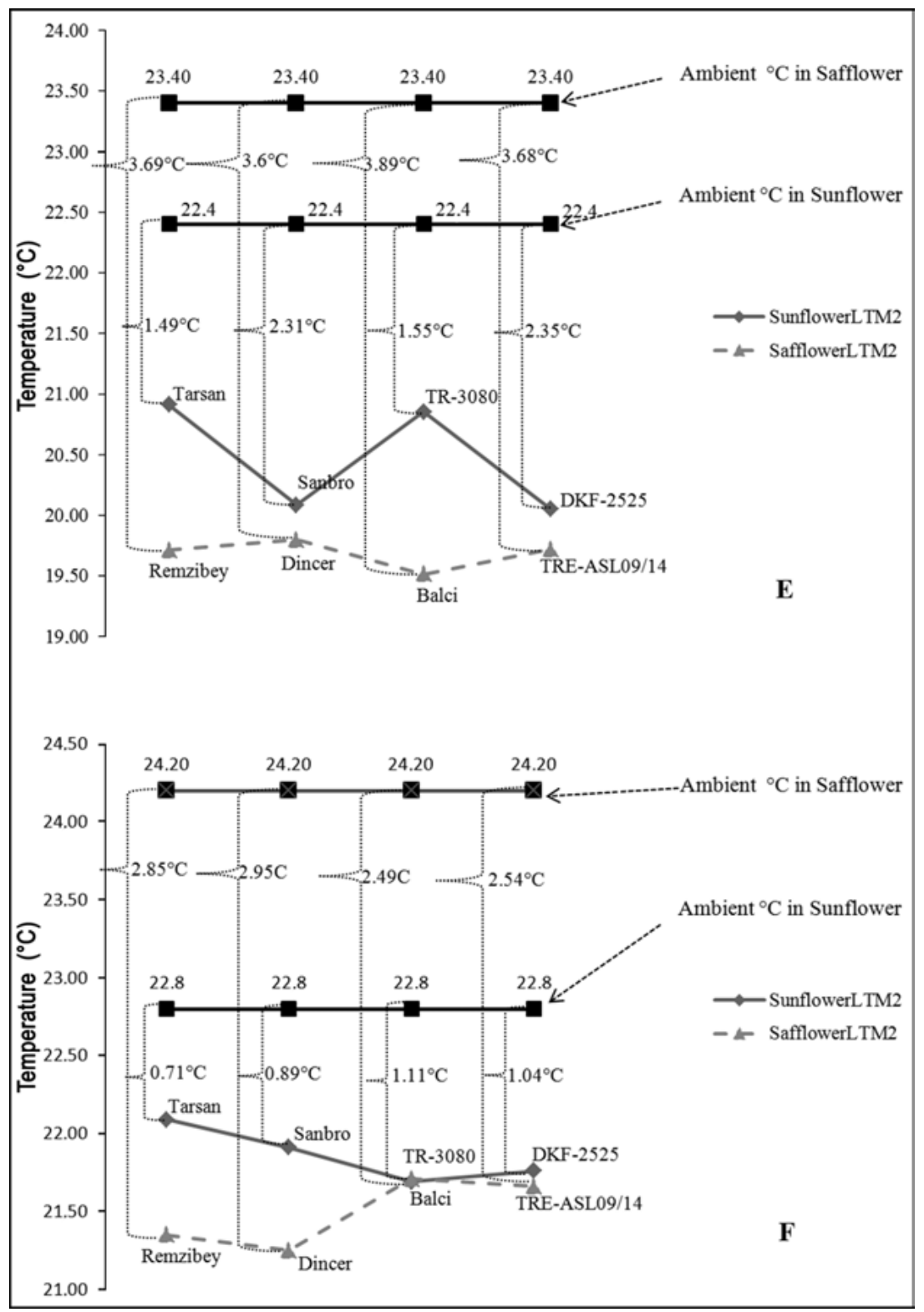

LSD $_{0,05}$ D: $0.161^{\star *}, \quad$ LSD $_{0,05}$ C: $0.228, \quad$ LSD $_{0,05} \mathrm{D}_{\mathrm{X}} \mathrm{C}: 0.322^{\star *}$ (for 8-10h) for Safflower LSD 0,05 D: $0.291^{\star *}, \quad$ LSD $_{0,05}$ C: $0.411, \quad$ LSD $_{0,05} \mathrm{D}_{\mathrm{X}} \mathrm{C}: 0.582$ (for 8-10h) for Sunflower

Figure 4: Leaf temperature of young fully developed sunlit leaves of four sunflower and safflower cultivars in the $8.00-10.00 \mathrm{~h}$ (LTM2) during $22.4^{\circ} \mathrm{C}$ (for Sunflower) and $23.4^{\circ} \mathrm{C}$ (for safflower) ambient temperature under well-watered and drought stress. (E: well-watered, F: drought stress). LTM2 was measured at $33^{\text {rd }}$ day after planting 
Table 2: The result of variance analyses for safflower leaf temperature measured two times under the well-watered and drought stress conditions

\begin{tabular}{lcccc}
\hline \multirow{2}{*}{ Variance Source } & \multirow{2}{*}{ d.f } & \multicolumn{3}{c}{ Calculated of Mean Square } \\
\cline { 3 - 5 } & & LTM1 & LTN1 & LTM2 \\
\hline D:S & 1 & $32.815^{\star *}$ & $49.908^{\star *}$ & $32.689^{\star *}$ \\
C & 3 & $0.270^{\star *}$ & $0.110 \mathrm{~ns}$ & $0.062 \mathrm{~ns}$ \\
D.S x C & 3 & $0.044 n \mathrm{~ns}$ & $0.295 \mathrm{~ns}$ & $0.268^{\star}$ \\
\hline
\end{tabular}

D.S: Drought Stress, C: Cultivars, d.f.: Degree of Freedom, ns: non-significant;

${ }^{*} \mathrm{P}<0.05 ;{ }^{\star \star} \mathrm{P}<0.01$, LTM: Leaf Temperature Morning (8-10h), LTN: Leaf Temperature Noon (13-14h)

\section{RESULT AND DISCUSSION}

Figure 1, which is the ambient relative humidity and temperature of greenhouse recorded 3 times a day after emergence (May-June), shows that statistical differences in terms of ambient temperature and relative humidity of greenhouse were not insignificant, in spite of having very small $R^{2}: 0.40$ and $R^{2}: 0.001$ during the experiment. These differences among days affected the leaf temperature of safflower and sunflower plants. Especially, a very high temperature and low relative humidity were recorded in the greenhouse at noon (data not shown). Drought effects on leaf temperature of sunflower and safflower, shown in Figure 2, 3 and 4, indicate that leaf temperatures of both sunflower and safflower under drought stress were higher than that of well-watered conditions during all measuring periods. The changes in leaf temperature were compared between well-watered and drought stress conditions. The leaf temperature of young fully developed sunlit leaves of sunflower and safflower was significantly increased in the drought stress condition during all measuring times (Figure 2B, 3D and 4F). Also it can be observed that there were high differences among sunflower genotypes in terms of leaf temperature in both drought-stress and well-watered conditions (Figure 4E and F). The result of our study shows that the leaf temperature of sunflower under drought-stress conditions was higher by 0.5 to $2^{\circ} \mathrm{C}$ than under well-watered conditions, similar to the previous findings (Hashimoto et al (1984); Orta et al., 2002). Nielsen and Anderson (1989) demonstrated that as stomata closed, leaf temperature increased in response to the leaf $\mathrm{CO}_{2}$ exchange rate declined by lower leaf water potential under water stress. Furthermore, lower leaf temperatures under drought-stress conditions could mitigate the heat stress, as an indication of how capable transpiration is to cool the leaves by reducing respiration as well as the loss of water across the cuticle, thereby improving WUE (Water Use Efficiency) (Tambussi et al., 2007). Also, Hashimoto (1982) noted that as the stomata were closed with ABA, variation in temperature across the leaves increased under the water stress. Slavik (1963) attributed that to cooling the leaves by significantly reducing the rates of photosynthesis and respiration. Hence the osmotic potential decreased under the drought stress condition. Especially, TRE-ASL09/14 breeding line genotype had a higher 
response to drought stress by increasing leaf temperature, not only in both measuring times (morning or noon), but also as compared to other genotypes.

Significant differences between the morning time (8-10 a.m.) and the noon time (1-2 p.m.) under the drought-stress conditions were observed in terms of leaf temperature of sunflower and safflower. Generally, both sunflower and safflower plants showed a higher leaf temperature during the 1-2 p.m. measuring time than that of the 8-10 a.m., because of the increase in the ambient temperature. The upper leaf surface tended to be warmer than the lower at the beginning of the day and when the soil water was adequate; otherwise there was little difference. This pattern seemed to reflect transpiration cooling and leaf position effects. During all measuring times, the leaf temperature of sunflower and safflower was lower than the ambient temperature. Pallas et al. (1967) pointed out that they were slightly below ambient, probably because of increased transpiration cooling. These data also show that the leaf temperature of young fully developed sunlit leaves of safflower was significantly increased by the drought stress condition, which was reflected in the amount of $0.7-2.5^{\circ} \mathrm{C}$ in both morning and noon measuring times (Figure 2A, B, Figure $3 \mathrm{C}, \mathrm{D}$ and Figure 4E, F). Especially, during the second measuring time, Balci and TRE-ASL09/14 safflower genotypes were statistically the first group in terms of leaf temperature in both morning and noon measuring times under the droughtstress conditions (Figure 4F) probably because of the increased transpiration cooling. And also, according to Khan et al. (2007) water-stress conditions resulted in considerable increase in leaf temperature and the drought tolerant genotypes and showed lower stomata conduct associated with warmer leaves, while in sensitive lines higher conduct and cooler leaves were recorded. Our results showed that differences between the safflower leaf temperature and ambient temperature were higher than differences between sunflower leaf temperature and ambient temperature in all measuring times (Figure 2A, B, Figure 3C, D, Figure 4E, F). Figure 2 showed that the performance of all sunflower and safflower genotypes under wellwatered conditions in the morning time (8-10 a.m.) showed the same performance under drought-stress conditions, while during the next measuring time there were significant differences. Figure 3 and 4 showed that TR-3080 sunflower hybrid cultivar fell into the first group statistically with the highest leaf temperature and the value near to ambient temperature (by $0.94^{\circ} \mathrm{C}$ under well-watered conditions) (Figure $3 \mathrm{C}$ ). It has low leaf temperature and the value far from the ambient temperature under the drought-stress conditions during the afternoon measuring time (Figure 3D). These data also show that significant differences in the leaf temperature depend on the duration of drought stress and actual performance of genotypes. Generally in all measuring time, the leaf temperature of sunflower showed the reaction closer to the ambient temperature than the leaf temperature of safflower (Figure 2A, B, Figure 3C, D and Figure 4E, F). Results revealed that the maximum increase (from 0.21 to $3^{\circ} \mathrm{C}$ ) in the stem temperature of sunflower was observed in the afternoon under the drought-stress conditions. Especially, the stem tempera- 

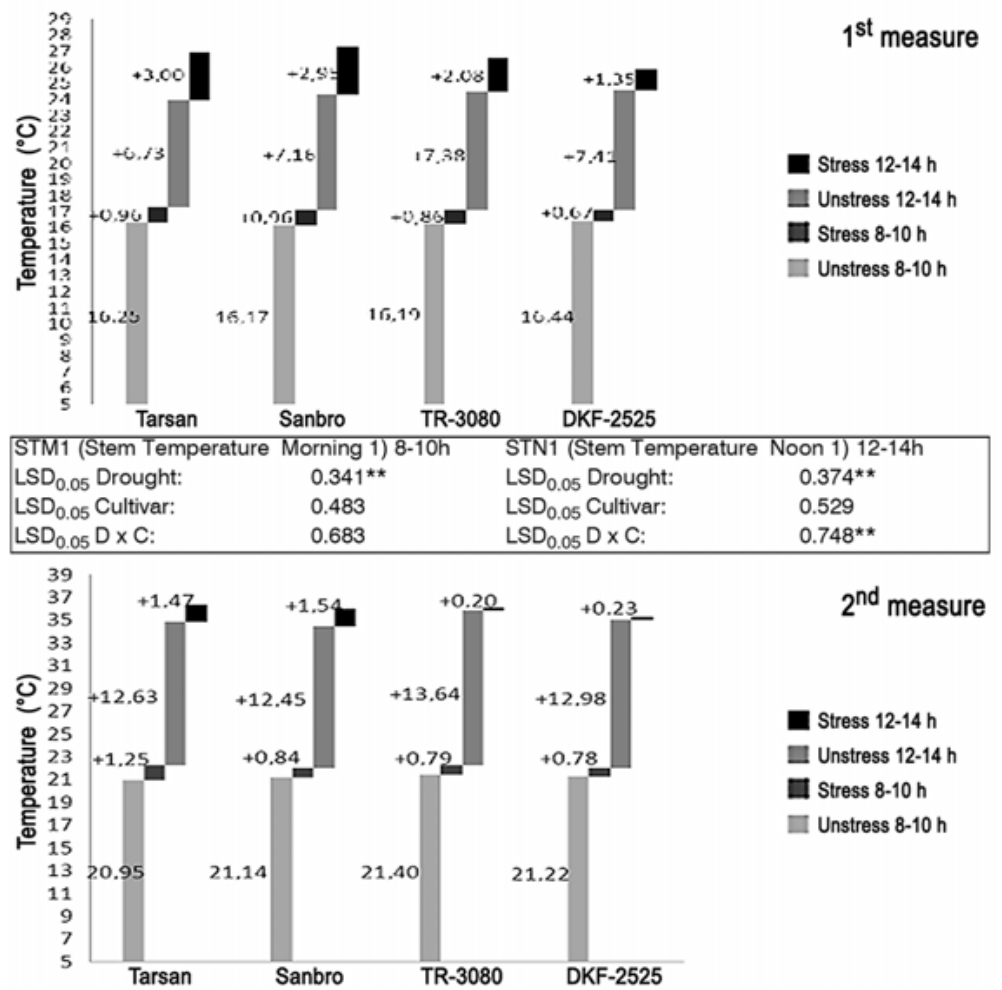

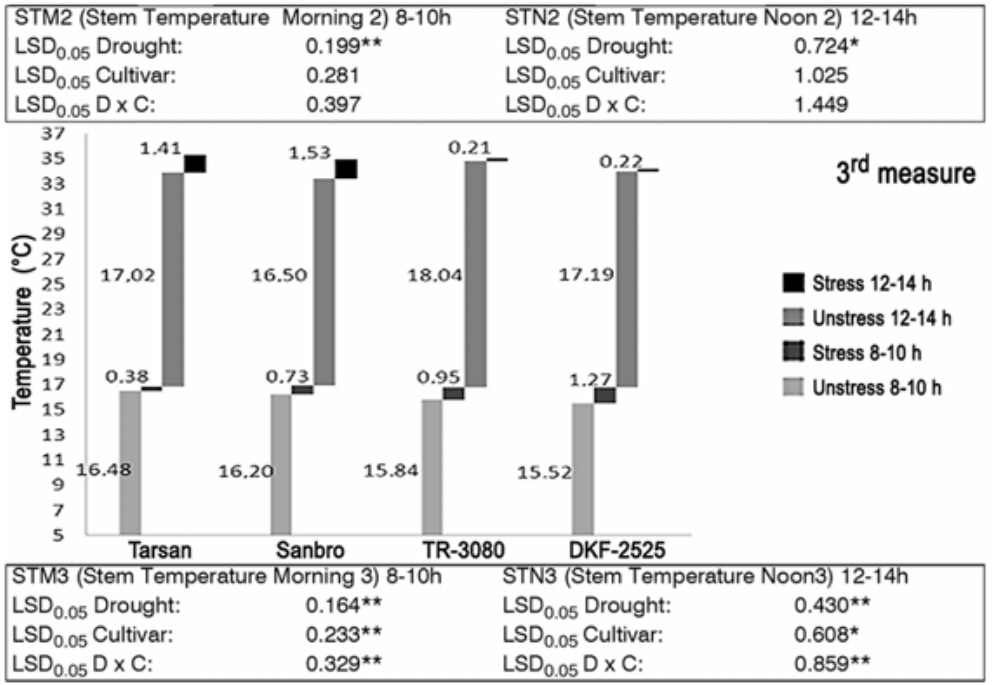

Figure 5: Stem temperature of sunflower under the well-watered and drought stress at 8 $10 \mathrm{~h}$ and at $12-14 \mathrm{~h} .1^{\text {st }}$ Measure: $26^{\text {th }}$ day after planting, $2^{\text {nd }}$ Measure: $33^{\text {rd }}$ day after planting, $3^{\text {rd }}$ Measure: $40^{\text {th }}$ day after planting. STM (Stem Temperature Morning) and STN (Stem Temperature Noon) 
ture of sunflower was significantly increased by drought-stress conditions in both morning and at noon, compared to well-watered condition. It can be showed in Figure 5 that all sunflower genotypes started to react against the drought stress in the last $\left(3^{\text {rd }}\right)$ measuring time, before the removal time. The highest increase in the stem temperature was observed in Sanbro cultivar (by $1.53^{\circ} \mathrm{C}$ under the drought stress conditions at noon). In contrast, Sanbro cultivar has the lowest stem temperature under the well-watering conditions at noon, but in the morning time, it has significantly the highest stem temperature as compared with the other cultivars. Although there is no knowledge in terms of stem temperature in literature, it can be concluded that the stem of a plant plays an important a role in many biological and physiological activities during the growth of sunflower because of the fact that ABA and water is transported in the xylem from roots to shoots, where it can cause stomata closure, decrease leaf expansion and thus preventing the dehydration of leaf tissues. Nezami et al. (2008) reported that the decrease of soil water content from 60 to $30 \%$ field capacity (FC) caused a $20 \%$ and $46 \%$ reduction in the stem diameter, as compared to the control one, respectively. Also these results are especially important owing to having high correlation between leaf and stem temperature when conducting the assessment of drought-stress conditions. Katerji et al. (1994) demonstrated that changes in stem diameter were well correlated with predawn leaf water potential under prolonged drought. As a consequence, the influence of drought stress on the stem temperature and leaf temperature of sunflower could be altered by many factors and their genetic properties during the day. Especially Sanbro sunflower cultivar showed parallel values in terms of leaf and stem temperature under drought stress in the first two measuring times (Figure 2B, 3D and Figure 5). The leaf temperature of Sanbro cultivars was in the first group in both morning and noon measuring times under drought-stress conditions and also it was the first group in terms of stem temperature under drought stress in the first two measuring times (Figure 5).

\section{CONCLUSION}

As a result of this study, single leaf temperatures measured with an infrared thermometer can provide a rapid means of assessing the plant water status in incomplete canopies. However, the leaf temperature might not be the only selection character, due to its defensive mechanisms in physiological characters associated with drought tolerance caused by very high complex. Therefore, a number of techniques and parameters, such as leaf water potential, leaf osmotic potential, canopy temperature and others must be used and measured to screen the drought tolerance in many crops. Also the comparison of infrared thermometer and infrared gas exchange fluorescence system analyzer may give better results in understanding the response of leaves against drought-conditions stress in future experiments. 


\section{REFERENCES}

Açıkgöz, N., Akba, M.E., Moghaddam, A. and Özcan K., 1994. Turkish data based statistics programmer for PC. Turkey Field Crops Congress, Ege University Press pp. 264-267.

Blum, A., 1989. Breeding methods for drought resistance. In: Jones, H.G., Flowers, T.J. and Jones, M.B. (eds.), Plant Under Stress. Cambridge Univ Press, UK. pp. 197-216.

Byrla, D.R., Bouma, T.J., Hartmond, U. and Eissenstat, D.M., 2001. Influence of temperature and soil drying on respiration of individual roots in citrus, integrating green observations into a predictive model for the field. Plant Cell Environ. 24: 781-790.

Gates, M.D., 1968. Transpiration and leaf temperature. Annu. Rev. Plant. Physiol. 19: 211-238.

Hashimoto, Y., Ino, T., Kramer, P.J., Naylor, A.W. and Strain, B.R., 1984. Dynamic analysis of water stress of sunflower leaves by means of a thermal image processing system. Plant Physiol. 76: 266-269.

Hashimoto, Y., 1982. Dynamic behaviour of leaf temperature. Biol Sci (Tokyo) 34: 68-75 (in Japanese).

Karschon, R. and Pinchas, L., 1969. Leaf temperatures in ecotypes of Eucalyptus camaldulensis Dehn. Zeitschriften Schweizerischen Forstvereins. 46: 261-269.

Katerji, N., Van Hoorn, J.W., Hamdy, A., Karam, F. and Mastrorilli, M., 1994. Effect of salinity on emergence and on water stress and early seedling growth of sunflower and maize. Agric. Water Manage. 26: 81-91.

Khan, H.R., Link, W., Hocking, T.J. and Stoddard, F.L. (2007) Evaluation of physiological traits for improving drought tolerance in faba bean (Vicia faba L.). Plant and Soil 292: 205-217.

Nezami H., Khazaei, R., Boroumand, R.Z. and Hosseini, A., 2008. Effect of drought stress and defoliation on sunflower (Helianthus annuus L.) in controlled conditions. Desert. 12: 99104.

Nielsen, D.C. and Anderson, R.L., 1989. Infrared thermometry to measure single leaf temperatures for quantification of water stress in sunflower. Agron J. 81: 840-842.

Orta, A.H., Erdem, T. and Erdem, Y., 2002. Determination of water stress index in sunflower. Helia. 25: 27-38.

Pallas, J.E., Michel, B.E. and Harris, D.G., 1967. Photosynthesis, transpiration, leaf temperature, and stomatal activity of cotton plants under varying water potentials. Plant Physiol. 42: 76-88.

Tambussi, E.A., Bort, J., Nogues, S., Guiamet, J.J. and Araus, J.L., 2007. The photosynthetic role of ears in C3 cereals: metabolism, water use efficiency and contribution to grain yield. Crit. Rev. Plant Sci. 26: 1-16.

Slavik, B., 1963. On the problem of the relationship between hydration of leaf tissue and intensity of photosynthesis and respiration. In: Rutter, A.J. and Whitehead, F.H. (eds.) The Water Relations of Plants. John Wiley \& Son, New York pp 225-234. 